\title{
Role of clusters in development of the digital ecosystem of the agro-industrial complex
}

\author{
Elena Dorzhieva*, Evdokia Dugina, Sayan Alexeev, and Nadezhda Bulatova \\ East Siberia State Technical University, Klyuchevskaya st., 40 v, 670013 Ulan-Ude, Russia
}

\begin{abstract}
The main trends in agriculture over the past few years have been export orientation and digitalization. Since 2019, the departmental project "Digital Agriculture" has been implemented. In 2021, a draft order of the government of the Russian Federation "On the Strategic Direction in the Field of Digital Transformation of the Agro-Industrial and Fishery Complex of the Russian Federation until 2030" was developed, which provides for development of a national online platform for promoting the agricultural products and the launch of a modeling and forecasting system for the agro-industrial complex. Currently, the beneficiaries of digitalization are large agricultural holdings and the IT industry (manufacturers of sensors and software developers for machinery and equipment, software companies, fertilizer producers and telecom operators). In order for small and medium-sized farms that do not have sufficient resources for end-to-end digitalization of production and business processes to be able to join the innovation race, it is necessary to look for a format of interaction in which competition and cooperation are organically combined. The article discusses one of such forms of association - clusters; explores their potential role in development of platform network architectures; the similarities and differences of cluster and digital industrial systems are analyzed. It is concluded that the flexibility and openness of cluster structures allows actors to find their functional areas and niches and organically fit into the created digital ecosystem of the agro-industrial complex.
\end{abstract}

\section{Introduction}

In the digital economy, the list of cluster policy tasks is expanding: clusters become both subjects of a single digital space and objects of use of digital technologies. As a result of the digitalization of global supply chains, transformation of traditional business models, formation of global networks of highly adaptive integrated companies, implementing "smart" distributed production, self-optimizing on the basis of autonomous "communication" between digital devices are taking place.

Clusters are distinguished by high adaptability, flexibility, allowing them to integrate into network structures and industrial systems, an organic combination of competition and cooperation, developing the ability to work in collaboration, informal relationships between

\footnotetext{
*Corresponding author: elendorg@mail.ru
} 
participants that contribute to formation of a culture of cooperation. Their role in development of Industry 4.0, which is fundamentally changing the paradigm of industrial development and blurring the boundaries between companies, sectors and regions, has not yet been fully defined. A number of researchers believe that clusters can become the core of platform network architectures [1,2,3].

\section{Materials and Methods}

The theoretical and methodological basis of the study was the papers of domestic and foreign scientists studying the peculiarities of the activity of clusters in the agro-industrial complex and the issues of managing the implementation and use of the ICT.

The instrumental and methodological apparatus is based on the basic methods of general scientific knowledge, theoretical, scientometric economic analysis, observation, generalization, abstraction, system analysis and synthesis, and expert assessment.

The studies used legislative and regulatory acts of the Russian Federation, data from ministries and departments, study results of the Higher School of Economics, institutes of the Russian Academy of Sciences, analytical reviews devoted to assessing the level of digitalization and clustering the Russian agro-industrial complex.

\section{Results and Discussion}

Blurring the spatial, temporal, industrial and sectoral boundaries leads to the fact that the staged value chain is gradually giving way to networks and further platforms [4]. Clusters, on the one hand, are geographically localized and have a key specialization, while digital industrial systems, due to remote interaction through Internet communications, carry out production everywhere and are focused on the diversification of activities. On the other hand, clusters and digital industrial systems have common characteristic properties (Table 1) [5].

Table 1. General properties of cluster and digital industrial systems.

\begin{tabular}{|c|c|}
\hline Cluster systems & Digital industrial systems \\
\hline $\begin{array}{c}\text { Cooperation and competition } \\
\text { between participants }\end{array}$ & $\begin{array}{c}\text { Concept of "connected enterprise", in accordance with which the } \\
\text { participants in the value chain interact with each other, while actively } \\
\text { practicing outsourcing and diversification of suppliers }\end{array}$ \\
\hline $\begin{array}{c}\text { Exchange of knowledge, } \\
\text { advanced technological } \\
\text { solutions, diffusion of } \\
\text { innovations }\end{array}$ & $\begin{array}{c}\text { High level of communication technologies, growth of network density } \\
\text { and intensity of network interconnections }\end{array}$ \\
\hline $\begin{array}{c}\text { Flexibility and adaptability of } \\
\text { cluster structures to changes } \\
\text { in external and internal } \\
\text { factors }\end{array}$ & $\begin{array}{c}\text { Mandatory requirement for participants is the ability to flexibly } \\
\text { integrate into existing networks of enterprises and timely adjust } \\
\text { strategies to achieve competitive advantages }\end{array}$ \\
\hline $\begin{array}{c}\text { Integration of production } \\
\text { processes opens up access to } \\
\text { resources and production } \\
\text { factors (components, } \\
\text { equipment, qualified } \\
\text { personnel) }\end{array}$ & $\begin{array}{c}\text { "Manufacturing as a service" model use is transforming manufacturers } \\
\text { into service providers seeking to personalize customer experiences } \\
\text { and diversify their businesses. This blurs the boundaries between } \\
\text { sectors and makes it possible to take advantage of the resources and } \\
\text { factors of the network participants on terms of lease, subcontracting, } \\
\text { arrangement of combined production, and etc. }\end{array}$ \\
\hline
\end{tabular}

Clusters can become a testing ground for digital solutions because:

- the cluster environment favors the transfer of knowledge, development of cooperation between science and business, expansion of personnel competencies 
(within the framework of Industry 4.0, reformatting of the labor market is inevitable, as a result of which a number of professions will disappear and the demand for highly qualified workers with a wide range of competencies will increase);

- due to the factor of spatial proximity, informal contacts with contractors arise, which are practically impossible to maintain in a remote format. Clusters can become a platform for implementation of large-scale projects that require cooperation with actors from other regions, entry into global value chains and transformation into geographic agglomerations [6, 7].

According to the IAS (Information and Analytical System) of the Russian Cluster Observatory and GISIP (Geographic Information System of Industrial Parks, Technoparks and Clusters of the Russian Federation), 10 clusters in Russia can enter the digital ecosystems of the agro-industrial complex: the agro-industrial cluster of the Novgorod region; aquaculture and fisheries of the Astrakhan region; cluster for production and processing the dairy products "Donskoe dairy products" of the Rostov region; dairy cluster of the Vologda region; food cluster of the Republic of Tatarstan; agro-industrial cluster "Kuban" in the Krasnodar Territory; wine territorial cluster "Don Valley" in the Rostov region; biotechnology (a cluster for deep processing of grain in the Millerovsky district of the Rostov region); agrobiotechnological industrial cluster of the Omsk region; territorial and sectoral cluster AGROPOLIS "ALKIAGROBIOPROM" in the Republic of Tatarstan.

The analysis showed that among ten Russian clusters producing agricultural products (with a total number of participating companies - 201 and the number of employees in these companies - 31,663 people):

- only 2 have reached the average level of organizational development (agroindustrial cluster "Kuban" and territorial-sectoral cluster AGROPOLIS "ALKIAGROBIOPROM");

- half (50\%) are regional ones; their participants do not include enterprises and organizations from other constituent entities of the Russian Federation;

-4 clusters (40\%) diversified their activities, covering a number of areas, which will be an advantage in formation of the national digital ecosystem of the agroindustrial complex.

The state agri-food policy is currently focused on the digital transformation of the agro-industrial complex with minimal participation of workers in production and business processes. The fourth industrial revolution affected all industries of the economy, including traditionally conservative agriculture. Use of innovative technologies, such as IoT (Internet of Things), AI (artificial intelligence), blockchain, makes it possible to create open digital platforms that cover all links and sectors of the agro-industrial complex and provide market players with a huge scope of options for making business decisions that provide a synergistic effect from expanding the interaction of industries and establishing a system of agri-food relations. The list of digital technologies that can be implemented in the agro-industrial complex is very extensive: from GIS (Geographic Information Systems) to the Internet of Things.

According to Order of the Ministry of Agriculture of the Russian Federation dated February 25, 2020 No. 84, a national platform "Digital Agriculture" shall be created by 2024, which will become the basis for building a whole ecosystem of additional services for the agro-industrial complex. In October 2021, the draft order of the government of the Russian Federation "On the Strategic Direction in the Field of Digital Transformation of the Agro-Industrial and Fishery Complex of the Russian Federation until 2030" was submitted for approval to the Ministry of Digital Development, Communications and Mass Media of the Russian Federation. The project 
provides for introduction of digital twin technologies, AI, IoT, drones, robotics, predictive analytics, remote sensing of the Earth; development of an online platform for promotion of Russian agricultural products and launch of modeling and forecasting systems.

However, directions of digitalization of the agro-industrial complex specified by the Ministry of Agriculture in the departmental project "Digital Agriculture", which is being implemented until 2024, raise many questions from practitioners. The criticisms point out that the digital technologies and solutions being introduced run counter to real optimization and savings, bringing benefits not to farmers, but to representatives of the IT industry. So, by 2023, the government plans to ensure the digitalization of reindeer herding farms ("Roadmap on the issues of indigenous peoples of the North, Siberia and the Far East of the Russian Federation in terms of development of animal husbandry"): $30 \%$ of the reindeer population owned by farms receiving state subsidies will be equipped with collars with radio beacons; at least $30 \%$ of reindeer farms will be equipped with quadrocopters; it is also planned to introduce support measures for operators providing satellite communication services to villagers and reindeer herders to ensure that nomadic and semi-nomadic people receive government services. According to preliminary estimates of experts, equipping a herd with a set of equipment costs about 2 million rubles, that is, in total, it will take about 1 billion rubles to arrange control and accounting. Meanwhile, the chairman of the board of the Association of Reindeer Herders M. Madejski expresses doubts about the technical feasibility and economic efficiency of this project, pointing out the more fundamental problems of the industry: transport and logistics, lack of specialists in reindeer farms, lack of mass demand for reindeer products, the need for protection livestock from predators [9].

In addition to ineffective public administration, barriers to digital transformation of the agro-industrial complex are as follows:

- low level of ICT penetration in rural areas and high tariffs for communication;

- low degree of processing and margins of the a-business, which makes the industry unattractive for investors;

- dependence on foreign equipment and technologies; non-customized foreign IT solutions;

- lack of funding and reluctance of agricultural companies to introduce digital technologies, lack of highly qualified personnel;

- heterogeneity and abundance of data in agriculture in the absence of effective tools for their processing;

- a lot of heterogeneous external factors that affect the yield and are often uncontrollable, which requires development of new digital forecasting methods;

- presence on the market of various platforms in absence of cross-platform solutions and industry standards; lack of information about existing solutions, manufacturers, implementation cases, achieved effects [10].

The most active implementation of digital solutions is carried out by agroindustrial holdings that have sufficient financial resources. Nevertheless, even large agricultural enterprises implement IT in fragments, there is no end-to-end digitalization of processes.

In terms of industries, the most in-demand technologies include:

- in agriculture - ERP (resource planning systems), satellite positioning technologies, equipment monitoring systems, field digitization, unmanned aerial vehicles; 
- in the dairy industry - elements of a "smart farm", intelligent production management systems and RFID systems (a method for automatic identification of objects);

- in the meat industry - robotization of processing.

At the moment, innovations in the agricultural sector are chaotic, the level of awareness and penetration of the offered products among farmers is not high enough. The average score of digitalization in Russian regions is 6.4 out of 10 , while the part of the regions that provide a large share of agricultural products is below the average score.

The digital divide is growing between agricultural holdings and small and mediumsized farms, which, due to a number of reasons (significant implementation costs, increased investment risks, lack of qualified personnel), cannot afford the large-scale use of digital technologies. Nevertheless, the potential demand for them from the agro-industrial complex is quite high: access to digital technologies offers advantages in terms of forming strategic partnerships, establishing relationships with suppliers, finding competent workers, openness of information, availability of support services, entering markets and arranging direct sales to consumers.

The digitalization vector in the agro-industrial complex can be represented as three steps for agricultural holdings and two steps (without the last one) for small and medium-sized agricultural producers (Table 2).

Table 2. Stages of digitalization in the agro-industrial complex.

\begin{tabular}{|l|l|}
\hline \multicolumn{1}{|c|}{ Stages/steps } & \multicolumn{1}{c|}{ Characteristics } \\
\hline $\begin{array}{l}\text { I. Agricultural } \\
\text { producer } \begin{array}{r}\text { with } \\
\text { efficient business } \\
\text { processes }\end{array}\end{array}$ & $\begin{array}{l}\text { Full integration of internal accounting systems, a single digital back } \\
\text { office, use of dashboarding, creation of a production database. }\end{array}$ \\
\hline $\begin{array}{l}\text { II. Digital technology } \\
\text { company }\end{array}$ & $\begin{array}{l}\text { Use of innovative technologies such as precision farming, artificial } \\
\text { intelligence, computer vision (CV), machine learning (ML), and etc. } \\
\text { Online supply chains, omnichannel sales (both offline and online). }\end{array}$ \\
\hline $\begin{array}{l}\text { III. Ecosystem of the } \\
\text { agricultural holding }\end{array}$ & $\begin{array}{l}\text { Formation of infrastructure for innovation. Integration of market } \\
\text { participants into a single system based on the digital platform of the } \\
\text { agricultural holding. Sale of digital solutions/services in the agro- } \\
\text { industrial complex is a separate area of activity. }\end{array}$ \\
\hline
\end{tabular}

To increase profitability, agricultural enterprises need to reach the second stage, and in 7-10 years, leadership in the industry will require the third stage of development. Currently, the overwhelming majority of Russian agricultural companies are faced with the tasks of the first two stages.

Note that the cluster creates conditions for development of all forms of farms within the most suitable market niche for them from the point of view of agroeconomic science and practice, using such a mechanism of interaction between small, medium and large enterprises as contracting.

Let us turn to foreign experience: agricultural holdings in the USA and Western European countries practice the so-called "incomplete" integration, in which the primary stage of agricultural production is an independent business process implemented by farmers (either through service cooperation or through contracting). The integrator, in turn, provides farmers with advice, maintenance, animals, and etc.

The advantages of "contract farming" are as follows:

- farmers become production partners of agricultural holdings, receive guarantees for sale of products and the possibility of technological renewal; 
- agricultural holdings may not invest additional funds in production assets and use high-quality, environmentally friendly raw materials.

In our opinion, cooperation and integration of large, medium and small businesses in the countryside (in the form of the same cluster associations) is a prerequisite for transition to a competitive agricultural model and sustainable agriculture in the context of digital transformation.

\section{Conclusion}

For the effective implementation of the main tasks - ensuring the country's food security, preserving rural areas, saving ecosystems - agriculture shall eliminate the digital divide between it and related industries. Currently, digital technologies in agriculture are being introduced pointwise, mainly by large agricultural holdings, which expect that digitalization will allow them to enter a new level of competition.

Industrial large and advanced medium-sized farms are the main industrial environment for implementation of the IT innovations, while small peasants and farms prevailing in Russia do not have sufficient financial capabilities to digitalize agricultural production. However, opposition of family commodity farms and large entrepreneurial structures is counterproductive: each organizational form occupies its own functional space, and mobilization of all resources and tools in order to develop one of them when causing collateral damage to the other will lead to a distortion of the multi-structured agricultural economy that threatens its stability. It is necessary to create conditions for development of all forms of farms, which is possible when arranging production and business processes using the cluster model. Clusters in the agro-industrial complex are hybrid structures, whose members include both agricultural holdings and farms, the effective interaction of which can be carried out through contracting. The flexibility and openness of cluster structures allows actors to find their functional areas and niches and fit organically into the digital ecosystem of the agro-industrial complex, which implies a transition from a linear type of business organization to a "platform" one by ensuring network interaction between manufacturers, suppliers and retailers, and includes a full life cycle from production, movement, consumption, to utilization of agricultural products.

\section{Acknowledgments}

This work was made within the grant "Young Researchers of the East Siberia State University of Technology and Management".

\section{References}

1. M. Brettel, N. Friederichsen, M. Keller, M. Rosenberg, International Journal of Mechanical, Aerospace, Industrial, Mechatronic and Manufacturing Engineering, 8, 37-44 (2014)

2. J. Alcácer, J. Cantwell, L. Piscitello, Journal of International Business Studies, 47, 499-512 (2016)

3. R. Strange, A. Zucchella, Multinational Business Review, 25, 174-184, 3 (2017)

4. M. Götz, B. Jankowska, European Planning Studies, 25, 1633-1653 (2017)

5. M. Götz, Foresight and STI Governance, 13, 72-83 (2019) 
6. F. Belussi, European Urban and Regional Studies, 12, 247-268 (2005)

7. M. Delgado, M.E. Porter, S. Stern, Defining clusters of related industries (NBER Working Paper 20375), Cambridge, MA, National Bureau of Economic Research (2014) http://www.nber.org/papers/w20375.

8. A. Konyavsky, Yu. M. Akatkin, E. D. Yasinovskaya, Information Security, 2, 14-16 (2018)

9. N. Korolev, A. Polukhin, Kommersant, 174/P, 7 (2021)

10. S. Vodianova, ICT Analytics and Digital Media. https://json.tv/. 